\title{
Remediation of Geogenic High Asenic Groundwater using Iron- based Nanomaterial Supported by Monolithic Structure
}

\author{
BING YAN $^{1 *}$, TIAN LIANG ${ }^{2}$
}

${ }^{1}$ School of Environmental Studies, China University of Geosciences, Wuhan 430074, PR China,

(*correspondence: yanbing@cug.edu.cn)

${ }^{2}$ Faculty of materials science and chemistry, China University of Geosciences, Wuhan 430074, PR China, (liangtian@cug.edu.cn)

Efficient Remediation of High Arsenic Groundwater Geogenic high arsenic groundwater is one of the global environmental geological disasters, which threatens global human health[1]. At present, Fe-based nanosorbents are being widely considered as an effective remediation materials for contaminated groundwater. However, practical application bottlenecks, such as low removal rate of As(III) and strong tendency to agglomerate, seriously restrict its application scope. In our study, a novel class of material (MFO/MPC), composed of Mn-doped nano FeOOH (MFO) supported on monolithic porous carbon(MPC), is developed for efficient arsenic removal. Unlike conventional nanosized remediation materials, MFO/MPC not only has the bifunctionality of oxidation and adsorption, but also possesses the property of anti-agglomeration, which turned out to be of great potential in the practical use for the remediation of geogenic high arsenic groundwater.

\section{Discussion of Results}

This bifunctionality of oxidation and adsorption show its excellent adsorption towards arsenic (maximum adsorption density: $152.5 \mathrm{mg} / \mathrm{g}$ for $\mathrm{As}(\mathrm{V})$ and $107.3 \mathrm{mg} / \mathrm{g}$ for $\mathrm{As}(\mathrm{III})$, respectively). At the same time, the kinetics study show that the concentration of $\mathrm{As}(\mathrm{V})$ can be reduced to the standard of WHO[2].

[1] Chen, C., et al. (2017) Appl. Surf. Sci. 425, 423-431.

[2] Habuda, M.\& Nujic, M. (2015) Environ. Sci. Pollut. Res.

Int. 22, 8094-8123. 